\title{
Polyurethane Acrylate/Montmorillonite Nanocomposites
}

\author{
Gonchar Oleksii*, Savelyev Yuri and Travinskaya Tamara \\ Institute of Macromolecular Chemistry of NAS, Ukraine
}

Submission: November 10, 2018; Published: December 05, 2018

*Corresponding author: Gonchar Oleksii, Institute of Macromolecular Chemistry of NAS of Ukraine, Kharkovskoe shosse, 48, 02160 Kyiv, Ukraine

\begin{abstract}
In order to create polymer nanocomposites with high performance on the basis of polyurethane acrylates (PUA) with montmorillonite (MMT), three methods of chemical modification of the layered silicate surface have been developed. The first modification method is based on using of two different functional modifiers (organophilic and reactive), the second method is based on modification with synthesized by us compound which contains urethane groups, and the third one in based on using synthesized by us modifier containing urethane and reactive groups. Exchange capacity of the MMT surface was determined by adsorption of indicator "methylene blue". Intercalation of modifier into the interlayer space of MMT was confirmed by X-ray analysis; the content of organic component in the modified MMT (MMT/M) was determined by thermogravimetric analysis. The resulting organoclay is purposed for the formation of nanostructured composites based on cross-linked polyurethane acrylates with improved physical and mechanical properties. The obtained polyurethane acrylate nanocomposites with different type MMT/M exhibit the increased in 1.6 - 2.6 times tensile strength as compared to original polymer matrix. WAXS method has proved an intercalation of modifier into MMT interlayer space (increased distance between layers after modification), as well as the total exfoliation of MMT in PUA matrix, characterized by the disappearance of the absorption peak which is responsible for layered structure.
\end{abstract}

Keywords: Montmorillonite; Modification; Polyurethane acrylate; Nanocomposites

Abbreviations: CTAB: Cetylammonium Bromide; DMF: Dimethyl Formamide; DMAEMAC: Dimethyl Ammonium Ethyl Methacrylate Chloride; DTA: Differential Thermogravimetric Analysis; HMDI: 1,6-Hexamethylene Diisocyanate; OUA: Oligourethane Acrylate; OUAC: Oligouretane Amonium Chloride; OUMAAC: Oligourethane Methacrylate Ammonium Chloride; POTMG-1000: Poly Oxytetra Methylene Glycol with Molecular Weight of 1000; NMDEA: N-Methyldiethanol Amine, Na-MMT; Na-form of Montmorillonite; MB: Methylene Blue; MDI - 4: 4'- Diphenylmethane Diisocyanate; MW: Molecular Weight; MWD: Molecular Weight Distribution; MMT: Montmorillonite; MMT/M: Modified Montmorillonite; PP: Prepolymer; PUA: Polyurethane Acrylates; WAXS: Wide-Angle X-ray Scattering

\section{Introduction}

Lately polymer-based nanocomposites are of great interest both in science and industry due significant improvement of performance of their properties compared to initial polymers and conventional macrocomposites. Polymer based nanocomposites are characterized by increased strength and heat resistance as well as reduction of gas permeability and flammability [1]. Creation of polyurethane acrylate (PUA) - organoclay based nanocomposites with high performance properties is a real chance to improve the basic properties of initial PUA polymer matrix. The increase of the strength and durability of PUA based materials may be achieved by incorporation of organoclay nanoparticles into the polymer matrix [2]. In order to modify the natural MMT by ion exchange method, it should be converted to the sodium (rarely to potassium) form by treatment with alkali metals carbonates [3], since the alkali metal cations are easier replaced on the organic cations compared to alkalineearth cations of natural MMT. In order to create polymer based on There are the following ways of MMT modification used in the field of polymer nanocomposites based on polar heterochain polymers:

a) modification with cationic surfactants (ammonium and phosphonium cations) [4]

b) modification with reactive compounds $[2,5]$.

c) modification with monomers during the reaction of polycondensation followed by the chain growth in the interlayer space $[1,6]$.

A disadvantage of the first method is nonpolar nature of the used surfactants. As a result of different nature of the organic modifier and polymer matrix the particles of modified MMT form an agglomerate that do not contribute to the intercalation and exfoliation of polyurethane into the interplanar space of MMT. Disadvantages of the second method are a small molecular size of reactive modifiers' molecules which does not provide a sufficient organophilicity of the mineral surface that complicates the penetration of the monomer molecules into the interplanar 
space. The same drawbacks are observed in case of the third modification method, namely modification with diamines, one of the amino groups of which is in a salt form and it is capable to ion exchange reactions in interplanar space of MMT. The sizes of the molecules of these monomers are not large enough to provide the sufficient organophilicity of MMT to overcome the agglomeration of the particles.

In order to create polymer nanocomposites with high performance on the basis of polyurethane acrylates (PUA) with montmorillonite (MMT), three methods of chemical modification of the layered silicate surface have been developed. The first modification method is based on combined modifying of MMT with two types of modifiers: cationic surfactant (cetylammonium bromide), which imparts organophilicity to MMT surface and facilitates dispersion of the mineral in organic medium; and a bifunctional amine - dimethylaminoethyl methacrylate. The developed method of MMT functionalization alows to obtain an organophilisized minerals containing reactive groups of different nature (acrylate, hydroxy, amine) on its surface, capable to participate in reactions of photoinitiated polymerization and polycondensation [7], which should increase the physical and mechanical properties of polymers. The second method of MMT modification lies in use of ammonium ions as surfactants, which include the urethane groups - oligouretane ammonium chloride (OUAC). Its molecule is sufficiently sterically large for provide the intercalation and exfoliation of MMT particles in polar organic media $[8,9]$. The new approach of MMT modification in contrast to the classical use of surfactants composed of ionic group and aliphatic large fragment (C12 - C20), consists in the use of synthesized by us surfactants with urethane groups in their structure. MMT modified with such cationic surfactants can form stable hydrogen bonds with polymer matrix: polyurethane, polyamide, polyamide, etc. Hydrogen bonding between the modified surface of MMT and polyurethane macromolecules provides a complete exfoliation of the modified MMT particles and strong physical interaction between inorganic and organic components. The high affinity of the modified nanofillers with polymer matrix provides the increased strength of polyurethane and other polar polymers-based materials. The third method. In order to create the nanofiller which form both physical and chemical bonds with polymer matrix, the new modifier oligouretane methacrylate ammonium chloride (OUMAAC) having both urethane and reactive methacrylate groups was synthesized $[10,11]$. The new modifier was synthesized by analogy with above mentioned OUAC.

Reactive methacrylate groups form chemical bonds with oligourethane acrylate matrix during the in situ polymerization. Modified surface of MMT nanoparticles, exfoliated due to the presence of urethane groups, provides not only physical but also chemical affinity with polymer matrix. Physical and chemical bonds of nanofiller with polyurethane acrylate matrix provides a significant increase of polymer nanocomposite service properties as compared to the initial polymer matrix.

\section{Materials and Methods}

We used a natural montmorillonite from clay deposit "Askaniya" (Georgia). MMT modifiers: cetylammonium bromide (CTAB) [Aldrich] and dimethylammoniumethylmethacrylate chloride (DMAEMAC) [Aldrich]. N-methyldiethanol amine (NMDEA) [Aldrich]; 1,6-hexamethylene diisocyanate (HMDI) [Aldrich] were used for synthesis of oligouretanamonium chloride (OUAC) nanomodifier. Isopropyl alcohol was distilled in the presence of anhydrous calcium chloride and fraction with $\mathrm{bp}=82^{\circ} \mathrm{C}$ was isolated. For the synthesis of OUMAAC nanomodifier, the N-methyldiethanol amine (N-MDEA) [Aldrich], 1,6-hexamethylene diisocyanate (HMDI) [Aldrich], hydroxyethyl methacrylate (HEMA) [Aldrich] were used. Polyoxytetramethylene glycol with molecular weight of 1000 (POTMG-1000) [Aldrich], 4, 4'- diphenylmethane diisocyanate (MDI) and HEMA [Aldrich] were used for synthesis of polyurethane acrylate (PUA). 2- propylolphenyl keton (Darokur-1173) was used as a photoinitiator of polymerization. To determine the exchange capacity of MMT the indicator of methylene blue (MB) (ZAT “Khimservice”, Russia) was used.

\section{Preparation of the sodium form of MMT}

The suspension of original MMT (5\%) in distilled water boiled for 1 hour with sodium carbonate in a weight ratio of MMT: sodium carbonate $=100: 1$ was used for obtaining of Naform of MMT (Na-MMT). The fourfold centrifugation, followed by washing with distilled water, was used to separate the resulting Na-MMT from the solution of sodium carbonate. The content of dry matter in Na-MMT suspension was defined gravimetrically. Modified MMT/M was then obtained using the resulting NaMMT suspension.

\section{Exchange capacity of Na-MMT}

Exchange capacity of the MMT surface was determined by adsorption of indicator "methylene blue" onto Na-MMT surface using photocalorimetry analysis [12] for calculation the modifier: MMT ratio. To determine the exchange capacity of MMT the estimation of adsorption of MB on the MMT surface was carried out, i.e. the dependence of the adsorption value on equilibrium MB concentration (the concentration of the solution on reaching the adsorption equilibrium). For that the eight samples of MMT with the same mass were filled up with the solutions of the same volume but different concentrations of MB. The equilibrium concentration was determined in three days. The adsorption $(\alpha, \mathrm{mmol} / \mathrm{g})$ was calculated as the difference between the initial amount of MB added to MMT suspension in solution with concentration $\mathrm{C} 0$ and the amount of $\mathrm{MB}$ remaining after adsorption onto $1 \mathrm{~g}$ of montmorillonite according to:

where: $\mathrm{C0}$ - initial concentration of MB;

$\mathrm{Cp}$ - equilibrium concentration of MB (per $1 \mathrm{~g}$ of MMT) after adsorption;

$\mathrm{V}$ - volume of an aqueous sample solution, l; 
g - mass of the MMT sample.

The equilibrium concentration increases sharply after adsorption raises more than $1.5 \mathrm{mmol} / \mathrm{g}$. That mean that exchange capacity of MMT used amounts to 1.5 [13]. The concentration of MB in solution was measured by photocolorimeter CK-2PM (PO "ZOMZ", Russia) after the separation of aqueous solution from the MMT.

\section{X-ray diffraction}

The polymer structure in the molecular level was studied by the wide-angle X-ray scattering technique (WAXS) using a DRON-4-07 diffractometer; X-ray optic scheme was arranged to operate in the transmission mode of the Debye-Scherrer method. CuK $\alpha$-radiation used as produced by an anode X-ray generator was monochromatized with a Ni-filter. The details of WAXS are presented in [14]. Scattered X-rays were detected with a scintillation counter in an automated stepwise scanning mode. The measured values of scattering intensity were corrected for attenuation of the incident X-ray beam by tested samples and subsequent deviation of the intensity of background X-ray scattering by the collimator system. The values of scattered intensity were normalized to the scattering volume. Finedispersed powders of MMT and MMT/M were placed into the cells. Registration of scattered intensity was carried out under condition of step-type scanning of scintillation detector in the scattering angles range from 2 to $40^{\circ}$. The distance (d) between layers of particles in the MMT was determined from Bragg's equation [15]:

$$
d=n \lambda(2 \sin \theta \max )^{-1}
$$

where $\mathrm{n}$ - the serial number of the diffraction peak in the diffraction patterns $(n=1), \lambda$ - wavelength of the characteristic X-rays (for $\mathrm{CuK} \alpha \lambda=0,154 \mathrm{~nm}$ ), $\theta$ - angle of X-ray scattering.

\section{IR-spectroscopy}

Samples of modifier were obtained on irtran substrate by pouring from an aqueous solution. FTIR spectra were measured using infrared Fourier transform spectrometer «Tensor-37» Bruker / FT-IR-Spectrometer (Germany) in the range of wave numbers of $4500-500 \mathrm{~cm}^{-1}$. The assignment of the bands was performed according to [16].

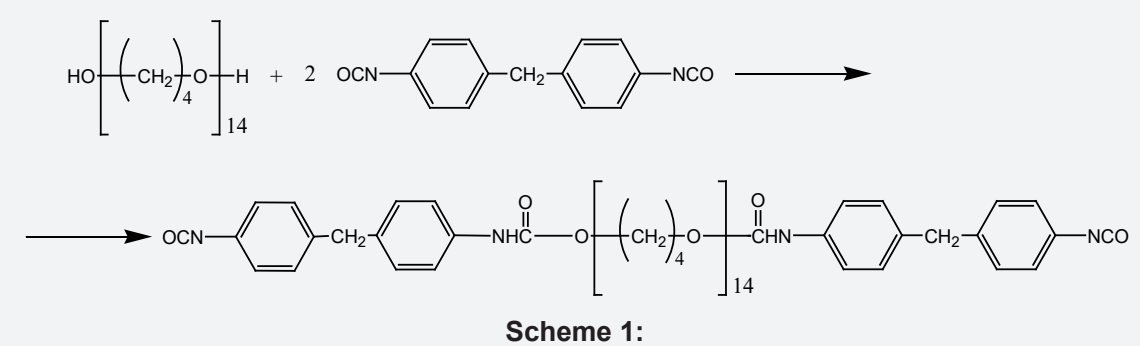

\section{Mechanical testing}

The tensile device FU-1000 (VEB MWK "Fritz Heckert", Germany) was used. The tensile speed was $100 \mathrm{~mm} \mathrm{~min}^{-1}$ and temperatue $25{ }^{\circ} \mathrm{C}$. For each measurement we used three samples. Samples were prepared in a form of strips (width - 4 $\mathrm{mm}$, operating length $-2 \mathrm{~mm}$ ). Measurements were carried out in accordance with Standard 14236-81; allowed error - 3\%.

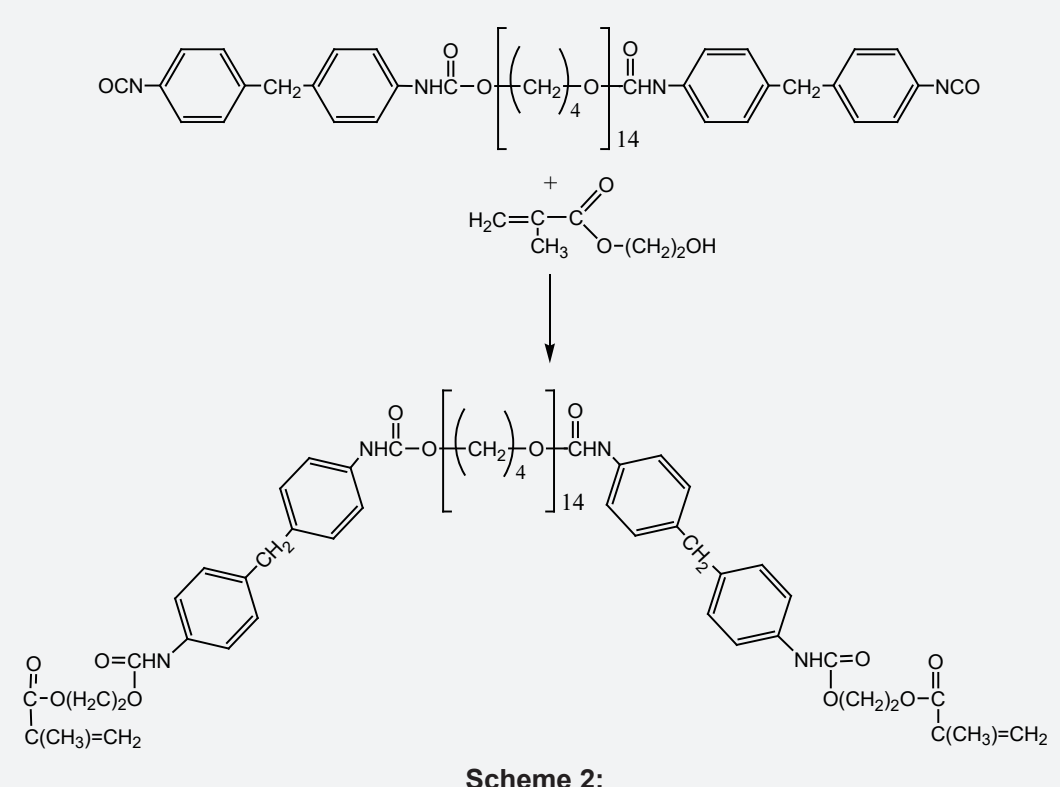




\section{Differential thermogravimetric analysis}

Differential thermogravimetric analysis (DTA) was carried out using a Q-1000 derivatograph, (MOM, Budapest) in the air under the following conditions: average heating rate $-10 \mathrm{deg}$ $\min ^{-1}$; temperature range: $20-1000^{\circ} \mathrm{C}$; the weight of samples: $100 \mathrm{mg}$; inert substance: $\mathrm{Al}_{2} \mathrm{O}_{3}$; sample holder: a ceramic conelike crucible.

\section{Prepolymer synthesis}

In order to obtain the prepolymer (PP) the initial components were placed into a three-necked reactor, equipped with inputoutput device of inert gas (argon) in amount corresponding to the ratio of their functional groups - $\mathrm{NCO}: \mathrm{OH}=2: 1$. The resulting mixture was heated under the continuous stirring at $80-85^{\circ} \mathrm{C}$ (30 min), followed by cooling the reacting mixture to $15^{\circ} \mathrm{C}$. The estimated content of isocyanate groups in the PP amounted to $6.3 \pm 0.1 \%$ wt. Scheme of PP synthesis is presented below: (Scheme 1)

\section{Synthesis of oligourethane acrylate (OUA)}

OUA was synthesized using MDI based PP. The calculated amount of HEMA in dimethyl formamide (DMF) was added to $\mathrm{PP}$ at the temperature of $55{ }^{\circ} \mathrm{C}$ under continuous stirring; the $\mathrm{NCO}: \mathrm{OH}$ ratio $=1: 1$. The process of OUA formation took no more than $1 \mathrm{~h}$ under the continuous stirring at $55{ }^{\circ} \mathrm{C}$.

Scheme of OUA preparation: (Scheme 2)

\section{Results and Discussion}

\section{Modification of Na-MMT with different types of modifiers}

The joint adsorption of components was studied using the method of two-phase titration with sodium lauryl sulfate in the presence of indicator MB, which was used for the selective determination of the concentration of the surfactant CTAB [12], which allows to determine the content of CTAB - the only one cationic component, which is a classical surfactant.

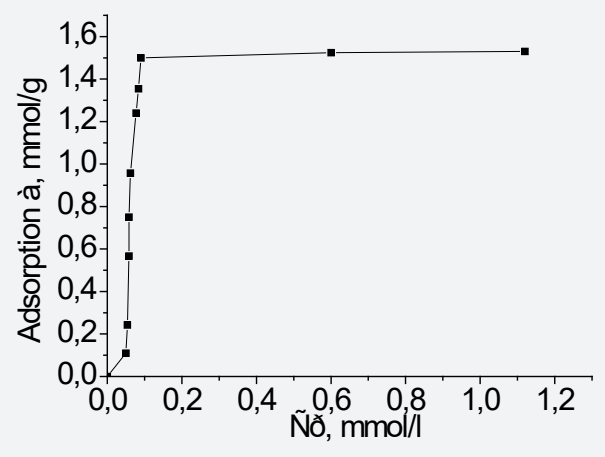

Figure 1: Adsorption isotherm of the mixture CTAB + DMAEMAC on sodium form of MMT.

In order to study the joint adsorption, the weighted amount of Na-MMT suspension was mixed with solutions of CTAB and
DMAEMAC (with different ratio of the latter). The amount of CTAB and DMAEMAC was equivalent to exchange capacity of MMT $(1.5 \mathrm{mmol} / \mathrm{g})$. To determine the equilibrium concentration of CTAB, the titration of the solution was carried out after attaining of adsorption equilibrium (in three days).

Two-phase titration of solutions after attaining of adsorption equilibrium showed that CTAB adsorbed on the Na-MMT regardless of DMAEMAC content in solution in an amount which corresponds to the exchange capacity of MMT $(1.5 \mathrm{mmol} / \mathrm{g})$. Adsorption isotherms of CTAB mixed with DMAEMAC have the same character as in the absence of the latter (Figure 1).

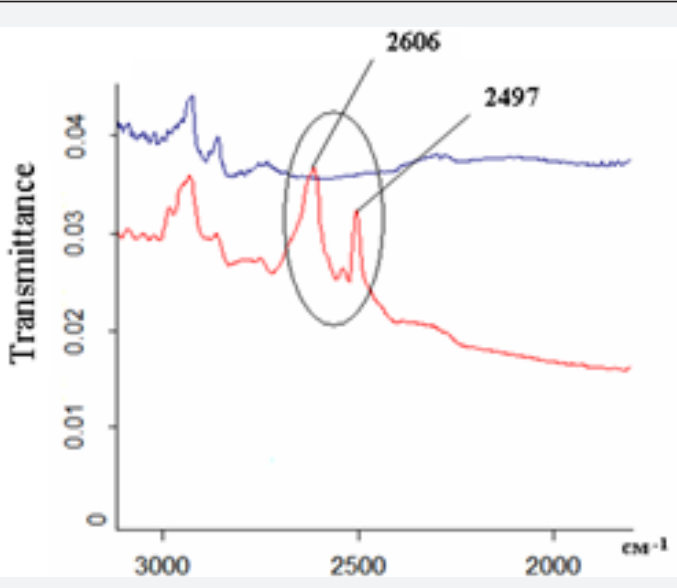

Figure 2: Fragments of FTIR - spectra of salts before and after attaining of adsorption equilibrium.

Thus, it has been found experimentally that CTAB as strong cationic surfactant capable to displace the DMAEMA ions from the montmorillonite surface. Therefore, modification with CTAB was carried out in an amount that corresponds to half of the ion exchange capacity of the mineral, and DMAEMAC addend was carried out with $30 \%$ excess per the residual ion exchange capacity, which was $50 \%$ of the initial ion exchange capacity of the mineral. To prove the simultaneous co-adsorption of both CTAB and DMAEMAC on the Na-MMT it was necessary to find a way of detection of DMAEMAC ions in aqueous solution. For this purpose, we used FTIR spectroscopy. Based on the fact that determination of the low concentrations of DMAEMAC using FTIR spectroscopy is not possible, we decided to analyze the dry residues of salts' aqueous solutions on irtran. FTIR data have shown, that dry residues of DMAEMAC solutions have a visible absorption band with maximum at $2497 \mathrm{~cm}^{-1}$ and $2532 \mathrm{~cm}^{-1}$ [16], corresponding to $\mathrm{NH}+$ of alkylammonium. Therefore, to prove the joint adsorption the weight amount of Na-MMT suspension was poured with a solution of CTAB and CTAB DMAEMAC in the ratio: CTAB - 0.75mmol/g MMT and DMAEMAC - $0.75 \mathrm{mmol} / \mathrm{g}$ MMT, respectively. Preliminary we obtained the FTIR spectrum of dry residue of DMAEMAC solution which was added to MMT. It can be clearly seen the absorption bands with maxima at $2497 \mathrm{~cm}^{-1}$ and $2532 \mathrm{~cm}^{-1}$ (Figure 2). After attaining of adsorption equilibrium (in three days) the FTIR spectrum of the dry residue of the solution displayed a complete absence of absorption 
bands that corresponded DMAEMAC. Thus, the adsorption of DMAEMAC was confirmed by comparative analysis of the FTIR spectra of salt solutions "before" and "after" attaining of adsorption equilibrium (Figure 2).

Absorption band with the maximum at $2606 \mathrm{~cm}^{-1}$ in the FTIR spectra (Figure 2) of dry residues of initial solution of amine salts indicates the presence of $\mathrm{NH}^{+}$of alkyl ammonium cation (bands at $2497 \mathrm{~cm}^{-1}$ and $2532 \mathrm{~cm}^{-1}$ ) whereas in sample after installing the adsorption equilibrium these bands are not found. MMT modification was carried out by adding the modifier solutions (CTAB and DMAEMAC) of preset concentration to aqueous NaMMT dispersion. After adding CTAB and DMAEMAC solutions the Table 1: Content of organic component in modified MMT. resulting mixture was diluted with distilled water to a ratio of $1 \mathrm{~g}$ MMT per $500 \mathrm{ml}$ of water. Modification was carried out for 48 hours, whereupon the precipitate of modified MMT was filtered, dried in an oven at $60{ }^{\circ} \mathrm{C}$ till constant weight and crushed in an agate mortar and in a ball mill. The content of organic component in modified montmorillonite was evaluated using TG data, (Table 1) as the difference between the mass of the sample "before" and "after" thermo destruction with regard to moisture content (0.5\%wt.). The content of organic component in the modified montmorillonite - amounts to $0.75 \mathrm{mmol} / \mathrm{g}$ for each of the two components and corresponds to the value of exchange capacity of montmorillonite surface.

\begin{tabular}{|c|c|c|c|c|}
\hline \multicolumn{2}{|c|}{$\begin{array}{c}\text { Adsorption of Organic Modifiers, } \\
\text { mmol/g }\end{array}$} & \multicolumn{2}{|c|}{$\begin{array}{c}\text { Theoretical Content of Organic } \\
\text { Modifiers, wt. \% }\end{array}$} & $\begin{array}{c}\text { Content of Organic Component in Accordance with } \\
\text { TG Analysis, \% }\end{array}$ \\
\hline CTAB & DMAEMAC & CTAB & DMAEMAC & Total \\
\hline 0.75 & 0.75 & 27.27 & 11.13 & 38.5 \\
\hline
\end{tabular}

\section{Modification of Na-MMT with oligouretane ammonium chloride (OUAC)}

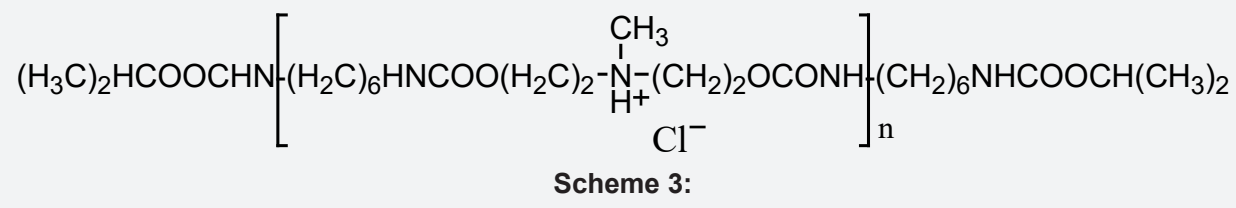

Based on the fact that chemical modification of MMT is carried out predominantly with aqueous solutions of cationic surfactants with a concentration below the critical micelle concentration, we have proposed a scheme for the obtaining of cationic surfactant (OUAC) solution, with a concentration of $4 \times 10^{-3} \mathrm{~mol} / \mathrm{l}$. OUAC synthesis was described in previous publication [13]. The structural formula of OUAC: (Scheme 3)

$\mathrm{n}=1-3$

Modification of MMT was carried out by addition to Na-MMT suspension of the solution of OUAC with $50 \%$ excess relative to calculated exchange capacity of Na-MMT. After adding an OUAC solution the resulting mixture was diluted with distilled water to a ratio of $1 \mathrm{~g}$ MMT per $500 \mathrm{ml}$ of water. Addition of OUAC solution to the MMT suspension resulted in instantaneous coagulation of MMT particles followed by formation of a white precipitate. Filtration, drying and grinding of the modified MMT was carried out by analogy with the previous method. To assess the content of the organic component in the modified MMT, the TGA study was conducted. TGA data showed that the organic part content was about $40 \%$ that substantially corresponds to its theoretical content.

\section{Swelling of modified MMT in organic solvents}

Swelling study of modified MMT in organic solutions showed that the modified MMT formed a stable gel in aprotic organic solvents such as dimethyl formamide and dimethyl sulfoxide. Gel formation indicates a high degree of solvent intercalation into the interlayer space of MMT and physical network formation.

\section{Modification of Na-MMT with oligouretane methacrylate amonium chloride (OUMAAC)}

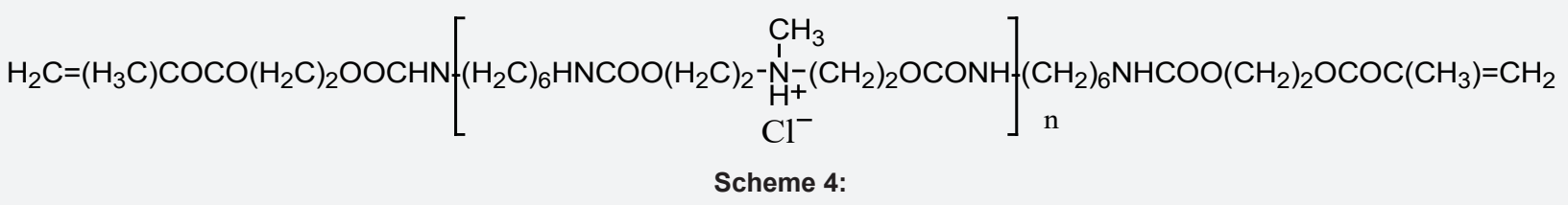

Preparation of cationic surfactant OUMAAC solution with a concentration of $5 \times 10^{-3} \mathrm{~mol} / \mathrm{l}$ was carried out similarly to OUAC. OUMAAC Synthesis was described in previous publication [17]. The MMT OUMAAC modification was carried out similarly to the OUAC modification. The structural formula of OUAC: (Scheme 4)

$\mathrm{n}=1-3$

\section{X-ray study of natural and modified MMT}

WAXS results (Figure 3) has shown, that modified MMT has a larger interlayer spacing $d_{001}$ in comparison with the original natural MMT $\left(\mathrm{d}_{001}=1.26 \mathrm{~nm}\right)$.

The distance between the MMT layers after modification increases up to $0.68-72 \mathrm{~nm}$. It should be noted that the 
"unification" of inorganic cations in the middle of the layers in case of Na-MMT reduces the interlayer distance d001 till $1.15 \mathrm{~nm}$. Thus, the effect of increasing of the interlayer distance of MMT as a result of modification with organic compound can be estimated as $0.79-0.83 \mathrm{~nm}$.

The increase in the interlayer distance of MMT $\left(\mathrm{d}_{001}\right)$ after the modification testifies to intercalation of organic modifier into the interlayer space.

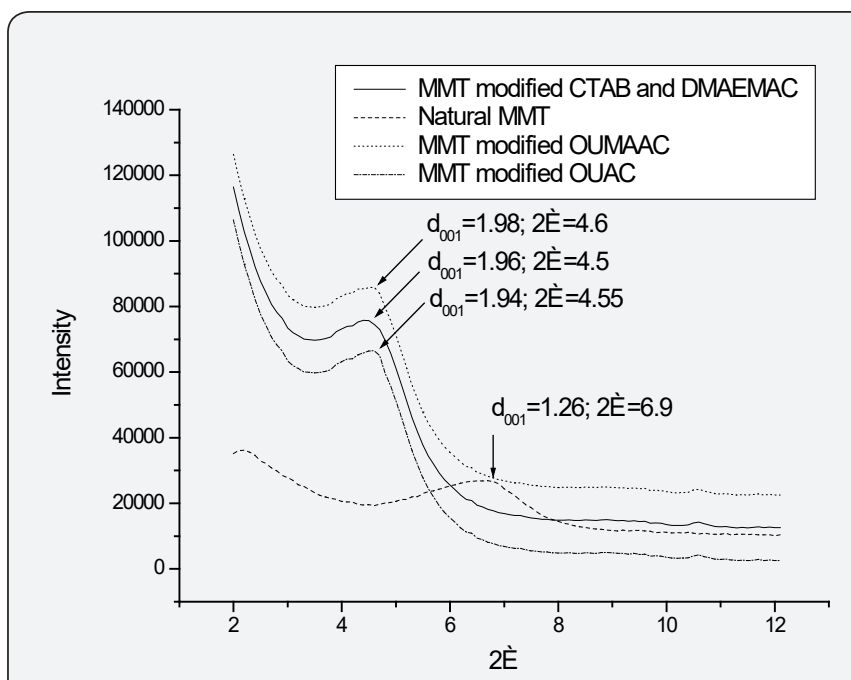

Figure 3: WAXS profiles of modified (a) and natural (b) MMT.

\section{Preparation of nanocomposites based on PUA and modified MMT}

Formation of nanocomposites based on PUA and modified MMT was carried out in a solution of organic solvent. In the case of MMT, modified jointly with CTAB and DMAEMAC we used toluene, in a case of MMT, modified with OUAC and OUMAAC we us dimethylformamide (DMF).

PUA and MMT/M based nanocomposites were prepared in toluene/DMF solution. Solution of toluene/DMF with calculated amount of OUA and modified MTT was sonicated in a glass container, then added to the reactor and stirred at $90{ }^{\circ} \mathrm{C}$ for five hours. Then the photoiniciator Darokur-1173 in the amount of $2.5 \%$ per OUA weight was added to the reaction mixture which was stirring for one hour. After stirring the resulting mixture in toluene/DMF solution was poured from the reactor into a conical flask with a stopper wherein the resulting mixture was settled.

Settled mixture was cast on glass Petri plates in equal portions to produce the films of uniform thickness. The films were formed by the gradual evaporation of the solvent under normal conditions. The resulting films were irradiated with a UVlamp for $30 \mathrm{~min}$ at irradiation intensity of $8 \mathrm{~W} / \mathrm{m} 2$. Conversion of methacrylate groups was determined by IR spectra: in $20 \mathrm{~min}$. the band corresponding to methacrylate groups has disappeared.

Thus, by photoinitiated polymerization of OUA the films of polymer matrix PUA and in situ nanocomposites PUA/MMT/M with the content of modified mineral of $2.5 \mathrm{wt} \%$ have been obtained.

\section{WAXS patterns of PUA/MMT/M nanocomposite}

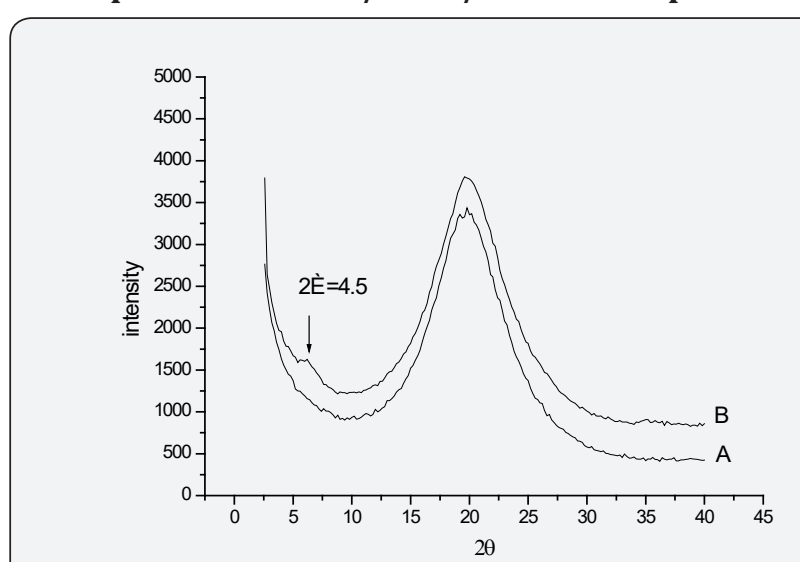

Figure 4: X-ray diffraction patterns of (A) PUA and (B) nanocomposite PUA/2.5\% MMT (CTAB + DMAEMAC)

It was found by WAXS method that exfoliation of nanofiller in MMT modified with CTAB + DMAEMAC based nanocomposite was not observed. Lack of exfoliation is illustrated by the presence of absorption peak characteristic for the modified MMT on the curve corresponding to the nanocomposite (Figure $4)$.

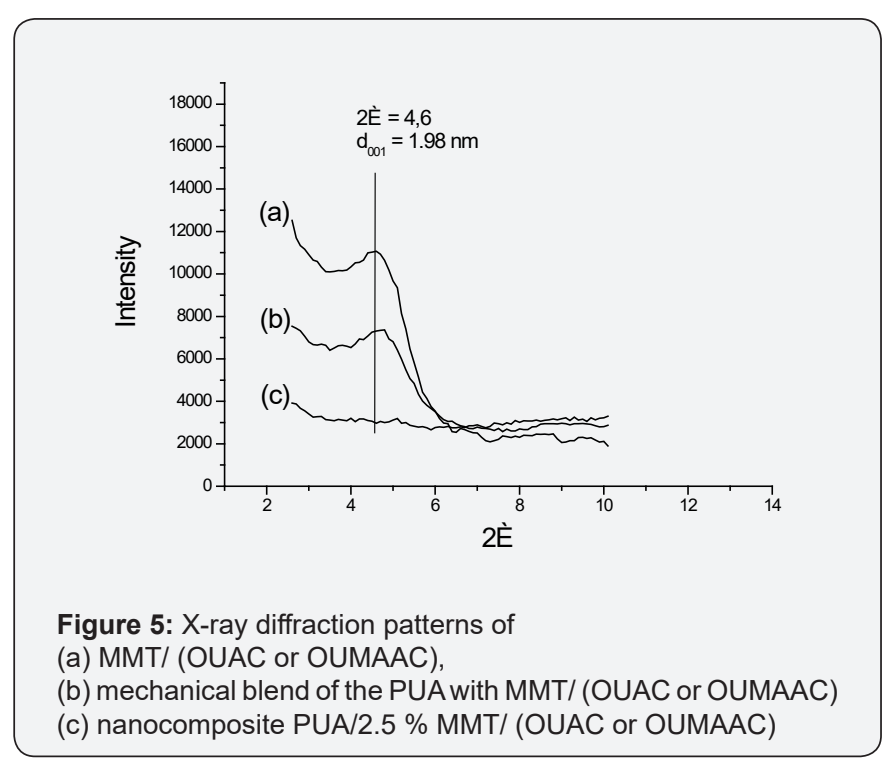

Unlike the first type of nanocomposite, the complete exfoliation of the nanofiller was observed for nanocomposites based on MMT modified with OUAC or OUMAAC. The absence of the characteristic absorption peak of the MMT/ (OUAC or OUMAAC) in nanocomposites' WAXS patterns (Figure 5) containing $2.5 \mathrm{wt} \%$ of the nanofiller, testifies to the it complete and systematic exfoliation in the PUA matrix. The absorption peak $2 \Theta=4.6$ in the diffraction pattern of mechanical mixture (b) is characteristic for the MMT/M, indicating that polymer matrix by itself does not affect the character of MMT (OUAC or OUMAAC) radiation absorption. 


\section{Physic-mechanical properties nanocomposites}

Comparative analysis of the tensile strength of all obtained nanocomposites with the same content of modified MTT $(2.5 \mathrm{wt} \%)$ has shown a significant increase of tensile strength relative to the original polymer matrix PUA (Figure 6).

It was found that nanocomposite with MMT (CTAB + DMAEMA) has in 1.9 times higher strength than that of the original PUA matrix. Increase of the strength of nanocomposite with MMT (CTAB + DMAEMAC) may be the result of chemical bonds formation between PUA and DMAEMAC on the MMT surface.

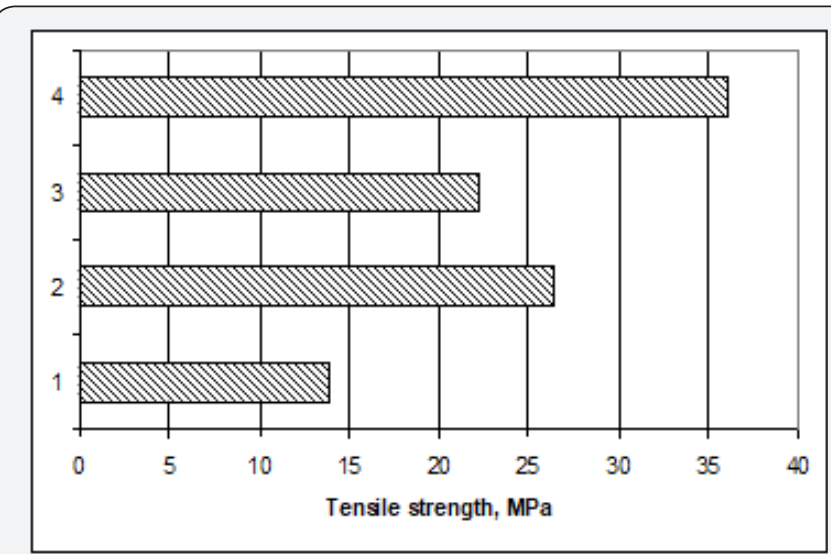

Figure 6: Tensile strength nanocomposites: 1 - PUA, 2 - PUA with MMT (CTAB + DMAEMA), 3 - PUA with MMT(OUAC), 4 PUA with MMT(OUMAAC).

Nanocomposite with MMT (OUAC) and nanocomposite with MMT (OUMAAC) possess the strength in 1.6 and 2.6 times higher than that of the original PUA matrix, correspondingly. Such difference in the results is probably due to the fact that MMT (OUAC) cannot form chemical bonds with PUA matrix.

Comparative analysis of the strength indices of all obtained nanocomposites has clearly illustrated the strengthening effect of reactive modifiers DMAEMAC and OUMAAC.

Nanocomposite with MMT (OUAC), despite the exfoliation of nanofiller and the formation of hydrogen bonds with PUA macromolecules, is inferior to nanocomposite with MMT (CTAB + DMAEMAC) for which the exfoliation of the nanofiller is not typical.

\section{Conclusion}

Three methods of chemical modification of the layered silicate surface have been developed.

a) New polyurethane acrylate nanocomposites based on newly created modified MMTs with high performance have been synthesized by in situ polymerization method.

b) The first modification method is based on using of two different functional modifiers (organophilic and reactive), the second method is based on modification with synthesized by us compound which contains urethane groups, and the third one in based on using of synthesized by us modifier containing urethane and other reactive groups.

c) Developed polyurethane acrylate/organoclay nanocomposites have shown a significant increase of strength indices.

d) The complete exfoliation of the nanofiller in nanocomposite based on MMT modified with OUAC or OUMAAC has been confirmed by WAXS.

Developed methods of montmorillonite modification are universal and can be applied to MMT of various origins (deposits).

\section{References}

1. Pavlidoua S, Papaspyridesb CD (2008) A review on polymer-layered silicate nanocomposites. Progress in Polymer Science 33(12): 11191198.

2. Nihan Nugay, Turgut Nugay, Joseph P Kennedy (2013) Minute amounts of organically modified montmorillonite improve the properties of polyisobutylene-based polyurethanes. Journal of Polymer Science Part A: Polymer Chemistry 51(19): 4076-4087.

3. Vishnu Mahesh KR, Narasimha Murthy HN, Kumaraswamy BE, Raghavendra N, Sridhar R, et al. (2011) Synthesis and characterization of organomodified Na-MMT using cation and anion surfactants. Frontiers of Chemistry in China 6(2): 153-158.

4. Adam Steele, Ilker Bayer, Eric Loth (2012) Adhesion strength and superhydrophobicity of polyurethane/organoclay nanocomposite coatings. Journal of Applied Polymer Science 125(S1): 446-452.

5. Shiwei Chen, Xuchen Lu, Zhimin Zhang, Tizhuang Wang, Feng Pan (2015) Preparation and characterization of poly (methyl methacrylate)/reactive montmorillonite nanocomposites. Polymer Composites 37(8): 2396-2403.

6. Suprakas Sinha Ray, Masami Okamoto (2003) Polymer/layered silicate nanocomposites: a review from preparation to processing. Prog Polym Sci 28(11): 1539-1641.

7. Yu V Savelyev, Gonchar OM, et al. (2008) Patent Ukraine 7346.Bul. № 22 (in Ukrainian).

8. Yu V Savelyev, Gonchar OM (2012) Patent Ukraine 74739. Bul. №21 (in Ukrainian).

9. Yu V Savelyev, Gonchar OM (2012) Patent Ukraine 74740. Bul. №21 (in Ukrainian).

10. Yu V Savelyev, Gonchar OM, M Yu Sokolov (2013) Patent Ukraine 80405. Bul. №10 (in Ukrainian).

11. Yu V Savelyev, Gonchar OM (2013) Patent Ukraine 80913. Bul. №11 (in Ukrainian).

12. Sanchez J, Beltran A, Alonso J, Jimenez C (1999) Development of a new ion-selective field-effect transistor sensor for anionic surfactants. Application to potentiometric titrations: Analytica Chimica Acta 382(12): $157-164$.

13. Savelyev Yuri, Gonchar Alexey, Travinskaya Tamara (2013) Montmorillonite Modified with Oligourethane Ammonium Chloride and Based Nanostructured Polymers. American Journal of Nanoscience and Nanotechnology 1(4): 87-93.

14. Yu S Lipatov, Shilov VV, Yu P Gomza, et al. (1982) X-ray diffraction methods for the study of polymeric systems. Nauk. Dumka, Kiev, Ukraine, (in Russian). 
15. Yoshiyuki Amemiya, Yuya Shinohara (2010) Small-Angle X-ray Scattering Basics \& Applications: Graduate School of Frontier Sciences. The University of Tokyo, Japan.

16. Colthup NB, Daly LH, Wiberley SE (1990) Introduction to Infrared and Raman Spectroscopy. In: Colthup NB, Daly LH, Wiberley SE (eds.), (3 ${ }^{\text {rd }}$ Edn), Academic Press Inc, USA

This work is licensed under Creative Commons Attribution 4.0 License

DOI: 10.19080/AJOP.2018.02.555582
17. Yu V Savelyev, Gonchar AN, Travinskaya TV (2015) New montmorillinite modifier for creation of polyurethane acrylate/organoclay nanocomposites by in situ polymerization. Journal of Chemical Engineering and Chemistry Research. 2(2): 511-520.

\section{Your next submission with Juniper Publishers will reach you the below assets}

- Quality Editorial service

- Swift Peer Review

- Reprints availability

- E-prints Service

- Manuscript Podcast for convenient understanding

- Global attainment for your research

- Manuscript accessibility in different formats

( Pdf, E-pub, Full Text, Audio)

- Unceasing customer service

Track the below URL for one-step submission https://juniperpublishers.com/online-submission.php 